\title{
Pengaruh Distribusi Zakat Produktif Terhadap Usaha Ekonomi Mustahik Di Kabupaten Bungo
}

\author{
Pini Susanti ${ }^{1}$ \\ Email: pinisusanti96@gmail.com \\ Isamuddin ${ }^{2}$ \\ Institut Agama Islam (IAI) Yasni Bungo \\ Email: isamuddin@iaiyasnibungo.ac.id.
}

\begin{abstract}
There are many factors that affect the growth of Islamic economics, one of which is the distribution of Zakat. Therefore, the researcher intends to conduct research at Baznas (National Zakat Agency) Bungo Regency which aims to determine the effect of productive zakat distributed by Baznas Bungo Regency on mustahik business. In this study, researchers used quantitative research methods, which were preceded by nonprobality purposive sampling and nonprobability incidental sampling. To collect data, researchers used a questionnaire (questionnaire), interviews and documentation. The data analysis technique used is descriptive analysis of respondents, descriptive variables and hypothesis testing. The data obtained were processed using statistical analysis using the SPSS version 21 application for windows. The results showed that the value obtained in the $F$ test is $F$ count $>F$ table, $(63,345>3,98)$ and the $t$ test shows the significance value obtained is $t$ count $>t$ table $(7,959>1,668)$ with a significance level of $0,000_{-}<-0.05$. Furthermore, through the determination test (R2) it is known that the effect of productive zakat on the development of the mustahik business is $48.6 \%$. Thus it can be concluded that the distribution of productive zakat has a significant effect on mustahik business.
\end{abstract}

Keywords: Distribution, Productive Zakat, Mustahik Business.

\begin{abstract}
Abstrak
Ada banyak faktor yang mempengaruhi Pertumbuhan Ekonomi Islam salah satu adalah pendistribusian Zakat. Oleh karena itu peneliti bermaksud untuk melakukan penelitian pada Baznas (Badan Amil Zakat Nasional) Kabupaten Bungo yang bertujuan untuk mengetahui pengaruh zakat produktif yang didistribusikan oleh Baznas Kabupaten Bungo terhadap usaha mustahik. Dalam Penelitian ini peneliti menggunakan metode penelitian kuantitatif, yang didahului dengan pengambilan sampel dengan metode Nonprobality purposive sampling dan Nonprobability incidental sampling. Untuk mengumpulkan data peneliti menggunakan kuesioner (angket), wawancara dan dokumentasi. Tehnik analisa data yang digunakan adalah analisis deskriftif responden, deskriftif variable dan uji hipotesis. Data yang diperoleh diolah dengan menggunakan analisis statistic dengan menggunakan aplikasi SPSS Versi 21 for windows. Hasil penelitian menunjukkan bahwa nilai yang diperoleh pada uji $\mathrm{F}$ adalah $\mathrm{F}$ hitung> $\mathrm{F}$ tabel, $(63,345>3,98)$ dan pada Uji $t$ menunjukkan nilai siknifikansi yang diperoleh sebesar $t$ hitung $>$ t table $(7,959>1,668)$ dengan taraf siknifikan sebesar $0,000<0,05$. Selanjutnya melalui uji determinasi (R2) diketahui Pengaruh zakat produktif terhadap perkembangan usaha mustahik sebesar 48,6\%. Dengan demikian dapat disimpulkan bahwa distribusi zakat produktif berpengaruh siknifikan terhadap usaha mustahik.
\end{abstract}

Kata Kunci: Distribusi, Zakat Produktif, Usaha Mustahik.

\footnotetext{
${ }^{1}$ Alumni IAI Yasni Bungo

${ }^{2}$ Dosen Institut Agama Islam Yasni Bungo
} 
Pini Susanti: Pengaruh Distribusi Zakat Produktif ....

\section{A. Pendahuluan}

Kesejahteraan sering diartikan sebagai suatu keadaan seseorang yang memiliki harta berlimpah dan hidup dalam kemegahan dengan kata lain mereka dapat memenuhi kebutuhan sehari-hari tanpa harus bersusah payah. Namun, hingga saat ini masih banyak masyarakat yang tidak dapat menikmati kehidupan yang sejahtera karena tidak mampunya memenuhi kebutuhan primer maupun sekunder sehingga menimbulkan persoalan kemiskinan.

Ada tiga kelompok ukuran kebutuhan minimum umat. Pertama, kebutuhan fisik primer yaitu kebutuhan berupa gizi seseorang, tempat tinggal, dan kesehatam. Kedua, kebutuhan kultural yaitu kebutuhan berupa ketenangan hidup dan pendidikan. Ketiga, yaitu kebutuhan yang berada lebih tinggi dari kebutuhan primer fisik dan kebutuhan kultural, artinya mereka yang memiliki kelebihan pendapatan. Tidak hanya itu, munculnya masalah ekonomi juga disebabkan adanya sekelompok umat yang tidak memiliki peluang usaha, aset produksi dan kemampuan mereka yang tidak memadai dalam mencapai kehidupan yang layak.

Pembangunan ekonomi merupakan suatu keharusan jika suatu negara ingin meningkatkan taraf hidup dan kesejahteraan rakyatnya. Dengan kata lain, pembangunan ekonomi merupakan upaya sadar dan terarah dari suatu bangsa untuk meningkatkan kesejahteraan rakyatnya melalui pemanfaatan sumber daya yang ada. Usaha-usaha pembangunan baik yang menyangkut sektoral maupun regional telah banyak memberikan hasil-hasilnya yang dapat dirasakan oleh seluruh lapisan masyarakat. Pembangunan bukan merupakan tujuan melainkan hanya alat sebagai proses untuk menurunkan kemiskinan dan mengurangi ketimpangan distribusi pendapatan. Jika pertumbuhan ekonomi yang tinggi tidak diikuti pemerataan hasil-hasil pembangunan kepada seluruh golongan masyarakat, maka hal tersebut tidak ada manfaatnya dalam mengurangi ketimpangan pendapatan. ${ }^{3}$

Mengingat ada banyak masalah dari BAZNAS di Kabupaten Bungo khususnya dan terbatasnya kemampuan serta biaya maka penulis perlu memberikan batasan masalah pada penelitian ini, sehingga tidak keluar dari masalah inti yang dibahas. Dalam penelitian yang akan dilakukan, masalah hanya fokus pada distribusi zakat produktif dan pengaruhnya terhadap usaha ekonomi mustahiq di kabupaten bungo.Dalam

${ }^{3}$ Pebrianita, "Pengaruh Zakat yang dikelola BAZDA Terhadap Pengentasan Kemiskinan dikota Padang”,(Skripsi, Program Strata S1 Ilmu Ekonomi Universitas Andalas, 2013), h. 9 
Pini Susanti: Pengaruh Distribusi Zakat Produktif ....

penelitian ini terdapat dua variable, yaitu distribusi zakat produktif (variable X) dan usaha ekonomi mustahiq (variable Y).

\section{B. Landasan Teori}

Dalam Kontek Pembangunan di Indonesia saat ini bahwa isu kemiskinan dan cara pengentasannya merupakan isu yang menonjol dan menjadi masalah sentral yang diselesaikan melalui berbagai Program pembangunan nasional. ${ }^{4}$ Terkait dengan persoalan tersebut Islam hadir dalam memberikan solusi terhadap kemiskinan, yaitu dengan cara mengoptimalkan pengelolaan zakat kepada yang dibebankan (muzakki) dan memberikannya kepada penerima zakat (mustahik), karena dari harta muzakki terdapat bagian yang menjadi hak orang lain.

Zakat bukan kewajiban yang hanya mengandung nilai teologis atau kewajiban saja, tetapi ada unsur hubungan manusia atau hablumminannas yang mengandung nilai sosial yang sangat berarti. Zakat merupakan mediator dalam mensucikan diri dan hati dari bakhil dan cinta harta serta merupakan suatu instrumen sosial yang digunakan untuk memenuhi kebutuhan dasar fakir miskin. ${ }^{5}$ Karena didalam harta seseorang terdapat hak-hak bagi orang-orang miskin, dan hal ini dijelaskan Allah swt dalam $\mathrm{Al}$ Qur'an.

Firman Allah SWT dalam Al Qur'an surah Adz Dzariyat ayat 19, yang menyatakan;

Dan pada harta-harta mereka ada hak untuk orang miskin yang meminta dan orang miskin yang tidak dapat bagian." (Q.S Adz Dzariyat: 19) ${ }^{6}$

Dana zakat yang dikelola dengan sistem dan manajemen yang amanah, profesional dan integral dengan bimbingan dan pengawasan dari pemerintah dan masyarakat akan menjadi pemacu gerak ekonomi didalam masyarakat dan menyehatkan tatanan sosial sehingga makin berkurangnya kesenjangan antara kelompok masyarakat yang mampu dan kelompok masyarakat yang kurang mampu. ${ }^{7}$

Di dalam Islam pemungutan zakat diambil dari pendapatan yang dihasilkan dari seluruh aset fisik dan finansial serta keahlian pekerja, dengan demikian potensi penerimaan zakat sangat signifikan dalam menurun angka kemiskinan. Untuk

\footnotetext{
${ }^{4}$ Ibid, .

5 Suratno, "Pengaruh Pendayagunaan Zakat Produktif terhadap Pemberdayaan Mustahik",(Skripsi, program Starta Satu S1 Ekonomi Syariah UIN Raden Intan Lampung, 2017), h.7 ART, 2004

${ }^{6}$ Departemen Agama Republik Indonesia, Al Qur'an dan terjemahannya, (Bandung: CV-Penerbit J-

${ }^{7}$ Suratno, "Pengaruh Pendayagunaan Zakat Produktif terhadap Pemberdayaan Mustahik",(Skripsi, program Starta Satu S1 Ekonomi Syariah UIN Raden Intan Lampung, 2017), h.7
} 
memaksimalkan potensi zakat dalam upaya meningkatkan kesejahteraan masyarakat, pengelolaan zakat sekarang ini dilakukan dengan dua cara, yaitu pengelolaan zakat secara konsumtif dan produktif. Pengelolaan zakat secara konsumtif yaitu pengumpulan dan pendistribusian yang dilakukan dengan tujuan memenuhi kebutuhan dasar ekonomi para mustahik berupa pemberian bahan makanan untuk dikonsumsi secara langsung, sedangkan pengelolaan zakat secara produktif yaitu pengelolaan zakat dengan tujuan pemberdayaan yang dilakukan dengan cara pemberian bantuan kepada pengusaha lemah berupa modal, pembinaan, pendidikan gratis, dan lain-lain. ${ }^{8}$

Zakat produktif merupakan zakat yang diberikan kepada mustahiq berupa modal usaha atau yang lainnya yang digunakan untuk usaha produktifyang mana hal ini akan meningkatkan taraf hidupnya, dengan harapanseorang mustahiq akan bisa menjadi muzakki jika dapat menggunakan hartazakat tersebut untuk usahanya. ${ }^{9}$

Di Kabupaten Bungo pengelolaan zakat dikelola oleh Badan Amil Zakat Nasional (BAZNAS), masyarakat percaya bahwa zakat yang dikelola oleh BAZNAS akan lebih optimal dan disalurkan sesuai ketentuan dan syarat yang berlaku. Pendistribusian yang dilakukan juga dengan cara produktif dan konsumtif, pemberian berupa produktif ternyata tidak dilakukan dengan cara mempublikasikan secara luas, karena kekhawatiran tidak cukupnya dana yang akan diberikan, sehingga sampai saat ini zakat produktif hanya diberikan kepada mustahik yang sudah memiliki usaha dan membawa persyaratan lengkap kekantor BAZNAS untuk mendapatkan bantuan modal. ${ }^{10}$

Tabel 1. Rekapitulasi mustahikzakat produktif pada tahun 2018
\begin{tabular}{|l|l|l|l|}
\hline No & Jenis Kelamin & Jumlah Mustahik & Jumlah Zakat \\
\hline 1. & Laki-Laki & 38 orang & Rp. 2.000 .000 \\
\hline 2. & Perempuan & 188 & Rp. 2.000 .000 \\
\hline
\end{tabular}

Data dari BAZNAS Kabupaten Bungo 2018

Setelah mengkaji beberapa literatur, penulis menemukan beberapa penelitian yang relevan jika disandingkan dengan Julnal ini. Penelitian Suratno ${ }^{11}$, yang berjudulPengaruh Pendayagunaan Zakat Produktif Terhadap Pemberdayaan Mustahik, dengan hasil penelitian bahwa pendayagunaan zakat produktif memiliki pengaruh positif dan signifikan terhadap pemberdayaan mustahik yang memberi pengaruh pendayagunaan zakat produktif terhadap pemberdayaan mustahik sebesar

${ }^{8}$ Ibid, h. 8

${ }^{9}$ Ibid,.

${ }^{10}$ M. Nuh, Wakil Ketua II di BAZNAS Kabupaten Bungo, wawancara di Bungo, Tanggal

${ }^{11}$ Suratno, "Pengaruh Pendayagunaan Zakat Produktif terhadap Pemberdayaan Mustahik", (Skripsi, program Starta Satu S1 Ekonomi Syariah UIN Raden Intan Lampung, 2017) 
Pini Susanti: Pengaruh Distribusi Zakat Produktif ....

35,6\%.Didalam penelitian ini memiliki persamaan yaitu menggunakan jenis penelitian lapangan (field research) dan variabel independen yang digunakan adalah zakat produktif. Adapun perbedaan dari penelitian ini bahwa lokasi yang diteliti oleh suratno di Lembaga Amil Zakat DUPDT Bandar Lampung.

Penelitian Gessy Evelin Miranda dengan hasil penelitiannya variabel zakat produktif berpengaruh signifikan terhadap perubahan pendapatan usaha sebelum dan sesudah menerima zakat produktif dari Badan Amil Zakat Nasional (BAZNAS). Adapun persamaan penelitian dari Miranda ialah menggunakan pendekatan kuantitatif, metode pengumpulan data (kuesioner dan dokumentasi), dan variabel yang digunakan. Adapun yang membedakan adalah lokasi yang digunakan berada di BAZNAS Jatinegara. Penelitian Mila Sartika ${ }^{12}$ dengan hasil penelitian bahwa adanya pengaruh signifikan antara jumlah dana yang disalurkan terhadap pendapatan mustahik sebesar 10,2\%.

\section{Metode Penelitian}

Penelitian ini termasuk dalam kategori penelitian jenis kuantitatif deskriptif dengan pendekatan penelitian lapangan (field research). Penelitian kuantitatif merupakan penelitian yang menggunakan metode statistik dalam meneliti. Populasi ${ }^{13}$ dalam penelitian ini adalah seluruh mustahik yang menerima dana zakat produktif di kabupaten Bungo.Sampel ${ }^{14}$ adalah sebagian yang diambil dari keseluruhan jumlah obyek yang diteliti yang dianggap mewakili terhadap seluruh populasi,yang dalam penelitian ini penentuan jumlah sampelnya menggunakan metodeslovin, dengan rumus sebagai berikut:

Keterangan :

$$
n=\frac{N}{1+N\left(e^{2}\right)}
$$

$\mathrm{n}=$ jumlah sampel minimal

$\mathrm{N}=$ jumlah populasi

$\mathrm{e}^{2}=$ persentase kelonggaran ketelitian karena kesalahan pengambilan sampel

dengan menggunakan metode slovin jumlah sampel pada penelitian ini dapat dihitung sebagai berikut:

$$
n=\frac{226}{1+226(0,1)^{2}}=69
$$

\footnotetext{
${ }^{12}$ Mila Sartika,"Pengaruh Pendayagunaan Zakat Produktif Terhadap Pemberdayaan Mustahik pada LAZ Yayasan Solo Peduli Sukarta”, jurnal ekonomi syariah, vol. II, no. 1

${ }^{13}$ Ibid.,h. 92

${ }^{14}$ Tukiran dan Hidayati Mustafidah, Penelitian Kuantitatif, Cet. 3, (Bandung:Alfabeta,2014),h.34
} 
Teknik pengambilan sampel yaitu metode nonprobability sampling yang merupakan teknik pengambilan sampel yang tidak memberikan peluang yang sama bagi setiap unsure (anggota) populasi untuk dipilih menjadi anggota sampel. ${ }^{15}$ Didalam penelitian ini menggunakan teknik sampling purposive dan sampling incidental.Sampling purposive adalah teknik untuk menentukan sampel dari populasi berdasarkan criteria atau pertimbangan tertentu.Sampling incidental adalah teknik penentuan sampel berdasarkan kebetulan, yaitu siapa saja yang secara kebetulan/incidental bertemu dengan peneliti dapat digunakan sebagai sampel, bila dipandang orang yang ditemukan sesuia criteria yang ditetapkan sebagai sumber data. ${ }^{16}$

Untuk menganalisis bagaimana BAZNAS kabupaten Bungo mendistribusikan zakat produktif dikabupaten bungo dalam rangka meningkatkan usaha mustahik, akan dianalisa menggunakan metode diskriptif dengan menampilkan data-data dalam bentuk table yang selanjutnya akan didiskripsikan pengertian dari data yang tercantum dalam penelitian tersebut.

Untuk mengetahui apakah ada hubungan distribusi zakat produktif yang dilaksanakan oleh BAZNAS terhadap usaha mustahik, akan dianalisa dengan cara metode statistik diskriptif, yaitu dengan pendekatan analisis regresi linier sederhana ${ }^{17}$. Dalam penelitian ini, analisis regresi linear sederhana berperansebagai teknik statistik yang digunakan untuk menguji ada atautidaknya pengaruh variabel $\mathrm{X}$ terhadap variabel Y. Variabel bebas (X) adalah Distribusi Zakat Produktif dan Variabel terikat (Y) adalah UsahaMustahik. Rumus regresi sederhana adalah:

Keterangan:

$$
Y=a+\mathrm{bX}+\mathrm{e}
$$

$\mathrm{Y}=$ subyek dalam variabel dependen yang diprediksi

$\mathrm{a}=$ harga $\mathrm{Y}$ bila $\mathrm{X}=0$ (harga konstan)

$\mathrm{b}=$ koefisien regresi

$\mathrm{X}=$ subyek pada variabel independen yang memiliki nilai tertentu

Untuk mengukur berapa besar kontribusi variabel independen mempengaruhi variabel dependen digunakan uji koefisien Diterminasi (R2)Semakin tinggi nilai koefisien

\footnotetext{
${ }^{15}$ Sugiyono, Statistik Nonparametris untuk Penelitian, h. 97

${ }^{16}$ Ibid., h. 98

${ }^{17}$ Ibid., h. 99
} 
Pini Susanti: Pengaruh Distribusi Zakat Produktif ....

determinasi, maka semakin tinggi kemampuan variabel independen mempengaruhi variabel dependen. ${ }^{18}$

\section{Hasil Penelitian Dan Pembahasan}

\section{Analisis Regresi Sederhana}

a. Uji regresi Linier Sederhana

Analisis regresidigunakan untuk menguji hipotesis tentang pengaruh secara pasrialvariabel bebas terhadap variabe terikat. Berdasarkan estimasi regresisederhana dengan program SPSS 21 for windows diperoleh hasil berikut ini:

\begin{tabular}{|l|r|r|c|}
\hline \multirow{2}{*}{ Model } & \multicolumn{3}{|c|}{ Coefficients $^{\mathbf{a}}$} \\
& \multicolumn{1}{|c|}{ Unstandardized Coefficients } & $\begin{array}{c}\text { Standardized } \\
\text { Coefficients }\end{array}$ \\
\cline { 2 - 4 } & $\mathrm{B}$ & Std. Error & \multicolumn{1}{c|}{ Beta } \\
\hline (Constant) & 6,727 & 2,276 &, 697 \\
X &, 535 &, 067 & \\
\hline
\end{tabular}

a. Dependent Variable: Y

Berdasarkan hasil uji pada tabel diatas, maka persamaan regeresi dapat dibentuk sebagai berikut:

$$
Y=6,727+0,535 X
$$

Keterangan :

$\mathrm{Y}=$ usaha ekonomi mustahik

$\mathrm{X}=$ distribusi zakat produktif

Dari persamaan tersebut, maka dapat dijelaskan:

1) Nilai konstanta adalah 6, 727. Artinya jika nilai distribusi zakat produktif tidak ada atau nol maka nilai konsisten usaha ekonomi mustahik sebesar 6,727.

2) Nilai koefisien regresi sebesar 0,535 artinya bahwa setiap peningkatan 1\% tingkat distribusi zakat produktif (X), maka usaha ekonomi mustahik (Y) akan meningkat sebesar $5,35 \%$

b. Uji T

Uji ini digunakan untuk mengetahui apakah dalam model regresi pada distribusi zakat produktif secara parsial atau keseluruhan berpengaruh signifikan terhadap usaha ekonomi mustahik.Hasil uji ini dapat dilihat pada tabel berikut:

\footnotetext{
${ }^{18}$ Ibid., h. 101
} 


\begin{tabular}{|c|c|c|c|c|c|}
\hline \multicolumn{6}{|c|}{ Coefficients $^{\mathbf{a}}$} \\
\hline \multirow[t]{2}{*}{ Model } & \multicolumn{2}{|c|}{ Unstandardized Coefficients } & \multirow{2}{*}{$\begin{array}{l}\text { Standardized } \\
\text { Coefficients } \\
\text { Beta }\end{array}$} & \multirow[t]{2}{*}{$\mathrm{t}$} & \multirow[t]{2}{*}{ Sig. } \\
\hline & $\mathrm{B}$ & Std. Error & & & \\
\hline (Constant) & 6,727 & 2,276 & & 2,955 & 004 \\
\hline $\mathrm{X}$ &, 535 & ,067 & 697 & 7,959 &, 000 \\
\hline
\end{tabular}

a. Dependent Variable: Y berikut:

Dasar pengambilan keputusan apakah hipotesis ditolak atau diterima sebagai

a. Jika $t_{\text {hitung }}<\mathrm{t}_{\text {tabel }}: \mathrm{H}_{0}$ diterima, artinya $\mathrm{H}_{\mathrm{a}}$ ditolak

b. Jika $t_{\text {hitung }}>t_{\text {tabel }}: \mathrm{H}_{0}$ ditolak, artinya $\mathrm{H}_{\mathrm{a}}$ diterima

Adapun tabel dengan taraf signifikansi 5\% atau 0,05 dan derajat kebebasan $(\mathrm{df}=$ $n-k$ atau 69-2=67). Dengan pengujian tersebut hasil yang diperoleh $t_{\text {tabel }}$ adalah 1,668.

Berdasarkan tabel diatas, terlihat bahwa hasil pengujian hipotesis distribusi

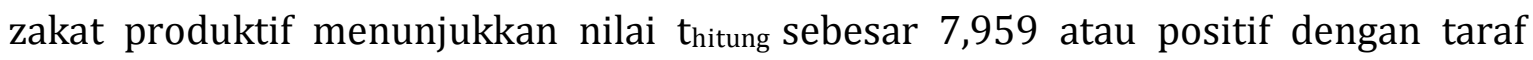
signifikan 0,000 . Maka $t_{\text {hitung }}>t_{\text {tabel }}(7,959>1,668)$ dan dengan taraf signifikan yang kurang dari 0,05 $(0,000<0,05)$. Dengan demikian, dapat diartikan bahwa hipotesis dalam penelitian ini menolak $\mathrm{H}_{0}$ dan menerima $\mathrm{H}_{\mathrm{a}}$.dapat dikatakan bahwa "distribusi zakat produktif memiliki pengaruh positif dan signifikan terhadap usaha ekonomi mustahik".

c. Uji F

Uji ini digunakan untuk mengetahui apakah ada pengaruh variabel bebas terhadap variabel terikat seacara simultas pada model regresi.Hasil uji $\mathrm{F}$ dapat dilihat pada tabel berikut:

ANOVAa

\begin{tabular}{l|r|r|r|r|r|}
\hline Model & Sum of Squares & Df & Mean Square & F & Sig. \\
\hline Regression & 261,120 & 1 & 261,120 & 63,345 &, $000^{\mathrm{b}}$ \\
Residual & 276,184 & 67 & 4,122 & & \\
Total & 537,304 & 68 & & & \\
a. Dependent Variable: Y \\
b. Predictors: (Constant), X
\end{tabular}

Dasar pengambilan keputusan pada uji ini adalah jika nilai $F_{\text {hitung }}>F_{\text {tabel }}$ dengan signifikan $<0,05$ maka variabel independen secara simultan berpengaruh terhadap variabel dependen. 
Pini Susanti: Pengaruh Distribusi Zakat Produktif ....

Berdasarkan hasil uji pada tabel diatas dapat diketahui bahwa nilai yang diperoleh $\mathrm{F}_{\text {hitung }} 63,345 \mathrm{~F}_{\text {tabel }}$ 3,98 dengan nilai signifikan 0,000 lebih kecil dari 0,05, maka variabel X secara simultan berpengaruh terhadap variabel Y.

d. Uji determinasi (R2)

Uji ini ditujukan seberapa besar variabel independen mempengaruhi variabel dependen.Nilai koefisien korelasi $\left(\mathrm{R}^{2}\right)$ ditentukan nilai adjusted $R$ square sebagaimana dapat dilihat pada tabel berikut ini :

Model Summary

\begin{tabular}{|l|r|r|r|c|}
\hline Model & R & R Square & \multicolumn{1}{|c|}{$\begin{array}{c}\text { Adjusted } \mathrm{R} \\
\text { Square }\end{array}$} & $\begin{array}{c}\text { Std. Error of the } \\
\text { Estimate }\end{array}$ \\
\hline 1 &, $697 \mathrm{a}$ &, 486 &, 478 & 2,03031 \\
\hline
\end{tabular}

a. Predictors: (Constant), $\mathrm{X}$

Hasil analisis determinasi dapat dilihat padatabel model summary dari hasil analisi regresi sederhan, berdasarkan analisis tersebut nilai R2 sebesar 0,486 (0,697 x 0,697) atau sebesar 48,6 \%. Hal ini menunjukan bahwa persentase sumbangan pengaruh distribusi zakat produktif (variabel independen) terhadap usaha ekonomi mustahik(variabel dependen) sebesar 48,6 \%. Sedangkan 51,4\% dijelaskan atau dipengaruhi oleh variabel lain yang tidak dijelaskan dalam penelitian ini.

\section{Pembahasan}

a. Bagaimana distribusi zakat produktif pada BAZNAS kabupaten bungo

Dari hasil penelitian penulis bahwa BAZNAS kabupaten bungo mendistribusikan zakat secara produktif dan konsumtif. Pendistribusian zakat produktif dilakukan secara langsung dengan mustahik sesuai persyaratan yang berlaku di BAZNAS, mustahikakan diminta untuk memenuhi persyaratan berupa surat permohonan bantuan dana untuk usaha, surat keterangan usaha dari kantor lurah, dan surat-surat sebagai identitas diri sebelum mendapatkan dana zakat produktif. Dana zakat produktif diberikan kepada mustahik yang telah memiliki usaha dan keadaan ekonomi yang kurang mampu. Jumlah dana zakat yang diberikan dilihat dari keadaan besar kecilnya usaha. ${ }^{19}$

b. Bagaimana pengaruh zakat produktif terhadap usaha mustahik di kabupaten bungo

${ }^{19}$ M. NUH, ketua II di BAZNAS kabupaten bungo, wawancaradi Bungo, pada tanggal 12 september 
Berdasarkan hasil uji statistik, dapat dilihat dengan jelas bahwa varibel independen berpengaruh terhadap variabel dependen. Pengaruh yang diberikan variabel independen tersebut bersifat positif yang berarti semakin tinggi distribusi zakat produktif maka akan mengakibatkan semakin tinggi perkembangan usaha mustahik, hasil penelitian ini sesuai dengan yang diajukan dan hasil penelitian terdahulu.

Kemudian hasil pengujian hipotesis dengan perhitungan yang diperoleh $t_{\text {hitung }}$ sebesar 7,959 dan $t_{\text {tabel }}$ sebesar 1,668 dengan hasil taraf signifikan 0,000 0,05 bahwa $t_{\text {hitung }}>t_{\text {tabel, }}$ dengan demikian $\mathrm{H}_{\mathrm{a}}$ diterima dan $\mathrm{H}_{0}$ ditolak. Dengan demikian, distribusi zakat produktif berpengaruh signifikan terhadap usaha mustahik di BAZNAS kabupaten bungo.

c. Berapa besar pengaruh pemberian zakat produktif terhadap usaha mustahik Berdasarkan hasil uji determinasi (R2) bahwa pengaruh zakat produktif terhadap usaha ekonomi mustahik sebesar 48,6 \%. Sedangkan 51,4\% dipengaruhi atau dijelaskan oleh variabel lain yang tidak dijelaskan pada penelitian ini, tetapi dibagi atas beberapa faktor yaitu sebagai berikut. Factor yang mempengaruhi pertumbuhan ekonomi :20

1) Tanah dan kekayaan alam

2) Mutu tenaga kerja dan penduduk

3) Barang modal dan tingkat teknologi

4) System sosial dan sikap masyarakat

Selanjutnya, distribusi karakteristik responden bahwa mustahik yang mendapatkan bantuan dana zakat produktif paling tinggi adalah mustahik dengan umur 39-49 tahun yaitu 20,01\% dan diperkuat dengan jenis pekerjaan mustahik yaitu Wiraswasta sebanyak 64 orang atau $44,16 \%$ dari jumlah sampel sebagai responden. Itu artinya, BAZNAS Kabupaten Bungo sangat memperhatikan keadaan mustahik yang mendapatkan bantuan zakat produktif tersebut sesuai pada umur yang memiliki tenaga cukup kuat dalam menjalankan usaha dan BAZNAS mengutamakan mustahik yang memiliki usaha sendiri.

${ }^{20}$ Ardra, "Faktor yang mempengaruhi pertumbuhan ekonomi." https://ardra.biz/ekonomimakro.com. Diakses pada tanggal 29 Januari 2019. 
Pini Susanti: Pengaruh Distribusi Zakat Produktif ....

\section{E. Kesimpulan dan Saran}

\section{Kesimpulan}

Berdasarkan hasil penelitian yang dilakukan penulis, bahwa secara parsial zakat produktif berpengaruh signifikan terhadap usaha mustahik, hal ini dapat dilihat dari hasil pengujian statistik yang diperoleh $t_{\text {hitung }}>t_{\text {tabel }}(7,959>1,668)$ dengan taraf signifikan sebesar $0,000<0,05$. Dan pada hasil perhitungan yang diperoleh $F_{\text {hitung }}>F_{\text {tabel }}$ $(63,345>3,98)$. Dengan demikian $\mathrm{H}_{\mathrm{a}}$ diterima dan $\mathrm{H}_{0}$ ditolak.

Selanjutnya, dari hasil uji determinasi (R2) bahwa pengaruh zakat produktif terhadap usaha ekonomi mustahik sebesar 48,6 \%. Sedangkan 51,4\% dipengaruhi atau dijelaskan oleh variabel lain yang tidak dijelaskan pada penelitian ini.

\section{Saran}

a. Bagi lembaga BAZNAS kabupaten Bungo

BAZNAS kabupaten bungo hendaknya lebih meningkatkan pendistribusian zakat dibidang produktif karena apabila usaha mustahikt berkembang, maka hal tersebut akan sangat membantu perekonomian mustahik dan akan terbentuknya para muzakki.

b. Bagi mustahik

Para mustahik yang mendapatkan bantuan dana zakat produktif hendaknya menggunakan dana tersebut sesuai dengan amanah yang diberikan, dan lebih ditingkatkan usaha yang dijalankan agar berkembang secara terus menerus.

\section{DAFTAR PUSTAKA}

Ardra, "Faktor yang mempengaruhi pertumbuhan ekonomi." https://ardra.biz/ekonomimakro.com. Diakses pada tanggal 29 Januari 2019.

Pebrianita, "Pengaruh Zakat yang dikelola BAZDA Terhadap Pengentasan Kemiskinan dikota Padang",Skripsi, Program Strata S1 Ilmu Ekonomi Universitas Andalas, 2013.

Gessy Evelin Miranda, "Analisis Pengaruh Pendayagunaan Zakat Produktif terhadap Perkembangan Usaha Mikro Mustahik", Skripsi, program Strata Satu Ekonomi Syariah UIN Syarif HIdayatullah.

Mila Sartika,"Pengaruh Pendayagunaan Zakat Produktif Terhadap Pemberdayaan Mustahik pada LAZ Yayasan Solo Peduli Sukarta”, jurnal ekonomi syariah, vol. II, no. 1.

Sugiyono, Statistik Nonparametris untuk Penelitian, (Bandung : Alfabeta, 2015), h. 13.

Suratno, "Pengaruh Pendayagunaan Zakat Produktif terhadap Pemberdayaan Mustahik",Skripsi, program Starta Satu S1 Ekonomi Syariah UIN Raden Intan Lampung, 2017.

Tukiran dan Hidayati Mustafidah, Penelitian Kuantitatif, Cet. 3, Bandung:Alfabeta,2014. 